\title{
The impact of face systems on the pragmalinguistic features of academic e- mail requests
}

Article

Accepted Version

Aslan, E. (2017) The impact of face systems on the pragmalinguistic features of academic e-mail requests.

Pragmatics and Society, 8 (1). pp. 61-84. ISSN 1878-9714 doi: https://doi.org/10.1075/ps.8.1.04asl Available at https://centaur.reading.ac.uk/67255/

It is advisable to refer to the publisher's version if you intend to cite from the work. See Guidance on citing.

Published version at: https://www.benjamins.com/\#catalog/journals/ps.8.1.04asl/details

To link to this article DOI: http://dx.doi.org/10.1075/ps.8.1.04asl

Publisher: John Benjamins

All outputs in CentAUR are protected by Intellectual Property Rights law, including copyright law. Copyright and IPR is retained by the creators or other copyright holders. Terms and conditions for use of this material are defined in the End User Agreement.

$\underline{\text { www.reading.ac.uk/centaur }}$ 
Central Archive at the University of Reading

Reading's research outputs online 


\title{
Pragmatics \& Society
}

Vol. 8, 2017

\section{The impact of face systems on the pragmalinguistic features of academic e-mail requests}

\section{Erhan Aslan \\ University of South Florida}

\begin{abstract}
This study investigates the impact of power/distance (PD) variables operationalized as face systems on the pragmalinguistic features of academic e-mail requests. A corpus of 90 academic e-mails was classified into four face system groups: hierarchical (sender $+\mathrm{P})$, hierarchical (recipient $+\mathrm{P}$ ), deference, and solidarity. Request perspectives, strategies, and mitigating supportive moves were analyzed. The analysis revealed that the speaker and hearer dominance were the most frequent request perspectives in the hierarchical (recipient $+\mathrm{P})$ and deference groups. The impersonal perspective was more common in the hierarchical (sender $+\mathrm{P}$ ) group. The preparatory was the dominant request strategy in all groups, relatively more frequent in the hierarchical (recipient $+\mathrm{P}$ ) and deference groups. The most common supportive move was the grounder, which occurred more frequently than other supportive moves. The findings of the study indicate that face systems influence the request patterns in academic e-mail communication. The study offers implications for future research on pragmatics of computermediated communication (CMC).
\end{abstract}

Key words: face systems, power/distance (PD), e-mails, requests, computer-mediated communication (CMC)

\section{Introduction}

New forms of technology facilitate communication in both synchronous and asynchronous modes and impact human communication in various practical and functional ways. Specifically, computer-mediated communication (CMC) as a form of computer-mediated discourse (Herring 2003) offers a variety of topics of investigation such as the relational aspects of language use, polite and impolite styles, different social and linguistic backgrounds and communities of practice (Locher 2010). Electronic communication is viewed as a socially situated discourse, and it encompasses both medium- and user-related phenomena (Herring 
2007). In other words, social variability and diversity in electronic language usage represents the discourse practices of different social communities.

Being a form of asynchronous mode of communication usually referred to as "Netspeak" (Crystal 2001), e-mail is now one of the most widely used means of electronic communication among various discourse communities, particularly in business and academic domains. E-mails are used for a wide variety of purposes such as making requests, asking for help, making excuses (Bloch, 2002), as well as making inquiries. Baron (1998) argues that e-mail enables users to establish and maintain social relationships by facilitating communication in various temporal and spatial domains. Indeed, due to the increase in the use of e-mails as a form of communication in various academic and business contexts, individuals are expected to conform to the "e-mail etiquette", specifically the use and appropriateness of language forms determined by the interpersonal relationships as perceived by the participants (Bjørge 2007).

Among the several factors affecting interpersonal relations between members of a discourse community are the power/distance (PD) variables. PD variables between members of a society are determined by marked differences in social status and individual needs and desires to maintain certain levels of relationships (French \& Raven 1959). While establishing or maintaining these relationships determined by PD variables, individuals exploit different linguistic resources. For instance, Holmes and Stubbe (2003) found that people that are institutionally ranked higher tend to use more explicit and direct forms in their requests than their addressee(s), and they clearly state what is asked or required of the addressee. On the other hand, when requestive acts or directives are performed by people ranked lower towards those with authority, different strategies of politeness are employed to mitigate the imposition of or soften the directness of the request. Thus, e-mail messages sent to those with authority tend to display greater formality, less directness, and use of more mitigation. By the same token, the communication style is also affected by PD differentials that individuals negotiate in CMC environments (Bjørge 2007; Verner \& Beamer 2005). As in face-to-face communication, the selection of linguistic forms or exploitation of pragmatic and discourse strategies bear importance in CMC environments, including e-mail communication.

Bou-Franch (2011) suggests that in order to understand the context-bound patterns of email communication, the structure and style of e-mail interactions should further be investigated. Additionally, how certain speech acts are performed in e-mails and whether PD variables among 
e-mail users influence the types, patterns, and perspectives of speech acts require further scholarly attention. To this end, the present study aims to contribute to the existing literature by operationalizing PD variables as face systems (Scollon, Scollon \& Jones 2012) analyzing the pragmalinguistic features in request e-mails of participants of academic discourse communities.

\section{Review of literature}

Several studies investigated the impact of the institutional or academic power differences between senders and recipients on e-mail interactions at the university level. Some of these studies focused on the e-mails between academic and non-academic staff members. For instance, Panteli (2002) found that e-mails sent by non-professorial staff to professorial staff within two academic departments lacked the use of signatures, and professors were less likely to use address forms than non-professorial members. She also found that some e-mails contained conversational features, incomplete sentences, and abbreviated forms, which all indicated informality. Though structured and formal, e-mails sent by non-professorial staff tended to be more personal and friendly and included address forms and greetings. In a similar study, Bou-Franch (2011) analyzed the opening and closing sequences in a corpus consisting of 240 short e-mail conversations in Peninsular Spanish between university lecturers from a discursive and sociopragmatic perspective. It was found that the openings and closings tended to be less elaborate and more intimate after the initial correspondence, lecturers preferred to adopt a more informal style of communication in the following interactions.

The impact of cross-cultural power differences on the interactions among university students was also studied. Examining the formality in domestic and international student e-mails to professors in Norway, Bjørge (2007) found that most students from high PD cultures ${ }^{1}$ chose a formal greeting and complimentary closing than students from low PD cultures, which suggests that national culture influences students' rapport management and discursive choices. Similarly, Liu (2011) investigated the impact of perceived power differentials on a semester long e-mail

\footnotetext{
${ }^{1}$ Bjørge's (2007) conceptualization of high/low PD cultures is predicated on Hofstede's (2001) work which views PD dimension as a cultural-level variable that is associated with inequality of power among the members of a society. Countries classified as having high PD culture include Azerbaijan, Belgium, Canada (French speaking), China, the Czech Republic, France, Ghana, Hungary, Jordan, Italy, Korea, Malaysia, Poland, Romania, Russia, Slovakia, Spain, Turkey, whereas low PD cultures include Australia, Austria, Britain, Canada (English-speaking), Finland, Germany, Israel, the Netherlands, Norway, Switzerland (German-speaking) and the US.
} 
communication between American and Taiwanese undergraduate students. The analysis of emails, students' reflections, surveys and semi-structured interviews revealed that both groups recognized asymmetrical power relations between each other in the e-mail writing activity. It was also found that the Taiwanese students developed different discursive and non-discursive strategies to deal with the power differentials. Investigating the cross-cultural variation in the (in)formality and (in)directness in email messages of Peninsular Spanish (PS) and British English (BE) speaking undergraduate students to their university lecturers, Lorenzo-Dus and Bou-Franch (2013) reported that both culture groups used informal greetings in the opening sequences. While PS students exploited directness in their requests and displayed more formality in supportive moves and closings, the BE students displayed more indirectness along with formal support moves and closings.

In the domain of student-faculty e-mail interactions, the request features have been extensively studied. Chen (2001) found that American and Taiwanese students' requests for appointment, recommendation letter and special issues differed in the amount of lexical and syntactic modification, whereas both groups preferred query preparatory strategies. Bou-Franch (2006) investigated the request patterns in a corpus of 20 e-mails sent by university students to her in the university lecturer capacity. Conceptualizing solidarity and deference as politeness resources, she analyzed the emails to see how each strategy was expressed in the emails. She found that solidarity and involvement were expressed in the opening sequences, whereas the expression of deference was more salient in the request sequences. Stylistic variety exhibited in native speaker (NS) and non-native speakers' (NNS) authentic performance on academic e-mail requests was documented by Biesenbach-Lucas (2007). Using Blum-Kulka, House, and Kasper's (1989) speech act analysis framework, Biesenbach-Lucas (2007) analyzed e-mail requests sent by NS and NNS graduate students to faculty at a major American university over a period of several semesters. The PD variable was defined by the institutional relationship: faculty having relative authority over students and social distance marked low due to the frequent and regular interaction between faculty and the students. The results revealed no significant differences between the levels of directness used by NS and NNS. Additionally, both NS and NNS students were aware of the situational factors and recognized differences among different request goals. Similarly, Economidou-Kogetsidis (2011) found that Greek Cypriot university students (NNSs of English) displayed a high degree of directness in requests for information and little use of 
lexical/phrasal downgraders as well as a lack of openings and closings and variation in address forms. Additionally, the most frequently used mitigation strategy was the grounder (which gives reasons for making the request). Studying the request patterns of Australian learners of Indonesian in everyday situations compared to Indonesian native speakers, Hassall (2001) also discovered a frequent use of the grounder as a request supportive move. In a more recent study, Soler (2013) found that international students preferred more direct strategies and external mitigators in their e-mails than British students, while both groups were found to be the same in their use of lexical and syntactic modifiers. Soler (2013) attributed the observed pragmalinguistic variation to participants' perceived social distance from the recipients and their lack of pragmalinguistic knowledge and perception of request imposition.

Studies reviewed in this section document how PD variables between members of academic discourse communities influence the pragmalinguistic features in e-mail communication. It seems that most research in the domain of email requests in academic settings mainly focused on non-native English speaking populations, specifically in student-faculty interactions with an interlanguage and cross-cultural pragmatics focus (Biesenbach-Lucas 2007; Bjørge, 2007; Bloch 2002; Economidou-Kogetsidis 2011). Although most previous research in this realm only controlled for the NS/NNS status of the students (email senders), such categorization for the university professors (email recipients) was overlooked. In this vein, in the present study, e-mail senders and recipients are considered to share English as an international language (EIL) regardless of their NS and NNS status. EIL refers to the notion that English is no longer restricted to native-speaking countries or cultures, and the number of non-native English speakers outnumbers that of native users (Selvi \& Yazan 2013). In this state of affairs, with its different varieties and users who come from various ethnic, cultural and social backgrounds, English now serves as an international or global language. Therefore, it is becoming increasingly difficult to categorize various World Englishes into native or non-native groups. To this end, the present study employs the face systems approach (Scollon, Scollon \& Jones 2012) as a theoretical framework that operationalizes PD variables on the basis of relational, personal, and group dynamics rather than NS/NNS or nationality status of e-mail users. Based on this framework, the goal of the present study is to examine how members of hierarchical, deference, and solidarity face systems exploit the pragmalinguistic features of e-mails of request specifically in the academic settings. The present study incorporates a variety of relationships 
between e-mail senders and recipients, thereby filling in a research gap which was called for in Lorenzo-Dus and Bou-Franch (2013). Specifically, this study investigates the following research question:

1) Are there any differences between the members of hierarchical, deference, and solidarity face systems in their use of pragmalinguistic features of academic e-mail requests with respect to:

a) request perspectives?

b) request strategies?

c) request mitigating supportive moves?

\section{Theoretical framework}

\subsection{Face systems}

From a sociolinguistic perspective, face is defined as "the public self-image everybody wants to claim for himself" (Brown \& Levinson, 1987: 61). The face systems approach to discourse and communication bears two dimensions as defined by Scollon, Scollon, and Jones (2012): 1) power (+P/-P) as a system in which participants acknowledge and respect hierarchical differences that situate individuals in higher or lower social ranks in relation to one another, 2) distance $(+\mathrm{D} /-\mathrm{D})$ as a system in which participants in a communication event usually share and negotiate certain assumptions and establish close or distant levels of relationships with each other depending on the nature, purpose, and context of communication. Furthermore, face systems also involve the concepts of involvement and independence (Scollon, Scollon \& Jones 2012). Involvement refers to a person's right or need to be a member of a society. Involvement can be shown through agreement, approval, or support in group interactions. Independence, on the other hand, refers to a person's need or right to be free and autonomous without having to conform to others' impositions or demands. A person can establish independence by showing respect for others' opinions, needs, and interests, maintaining a personal space, or giving them options (Paltridge 2012). The face systems approach establishes a connection between politeness and language use and can be helpful in the analysis of the speech act of requests since this particular speech act may arguably be influenced by PD variables.

Scollon, Scollon and Jones (2012) describe three types of face systems: hierarchical, deference, and solidarity. Hierarchical face systems include relationships in which participants recognize social status or rank differences (+/-P), but the distance between the participants is less 
relevant (+/- D). Hierarchical face systems are quite common in organizational relationships in business, governmental, and educational contexts. Deference face systems involve relationships in which participants have no power difference (-P or symmetrical) but distant independence $(+\mathrm{D}$ or distant). For instance, colleagues who have never met each other before $(+D)$ will assume the same power (-P). Solidarity face systems involve close relationships in which participants know each other and feel neither a power difference (-P) or distance (-D) between each other.

\subsection{The CCSARP project and the speech act of request}

The aim of the CCSARP project (Blum-Kulka, House \& Kasper 1989; Blum-Kulka \& Olshtain 1984) was to investigate speech act variation across languages, social variables, and NS and NNS performance. The coding manual generated for this project has been extensively used in field of interlanguage pragmatics research specifically to analyze request patterns in nonmediated discourse (Lorenzo-Dus \& Bou-Franch 2013). According to the CCSARP coding manual, the analysis of request realization involves three main components: These are request perspectives, request strategies, and request supportive moves.

The request perspective refers to the viewpoint of sender, recipient, or both participants as well as explicit presence or deliberate avoidance of the participants corresponding with one another. There are three types of request perspectives: 1) hearer dominance (explicit mentioning of the recipient by the sender), 2) speaker dominance (sender explicitly referring to him/herself), 3) speaker/hearer dominance (the use of pronoun "we"), 4) impersonal (avoidance of any agents or participants).

The request strategies refer to the particular choices of level of directness in the realization of request. There are nine types of request strategies: 1) mood derivable (the imperative form or elliptical sentence structures), 2) explicit performative (the explicit use of an illocutionary verb in the request), 3) hedged performative (the use of either modal verbs or other expressions of intention to soften the illocutionary force of the request), 4) locution derivable (the requestive intent can be drawn from the semantic meaning of the locution), 5) want statement (a desire for the requested act to take place is expressed in the utterance, 6) suggestory formula (suggestion is made for the requested act to take place in the utterance, 7) preparatory (conditions for the feasibility of the request are referred to in the utterance), 8) strong hint (the illocutionary force of the requested act is not explicitly stated but it is to be inferred by the hearer through preconditions for the feasibility of the request), and 9) mild hint (no elements relevant to 
the intended proposition, therefore, the recipient must rely on contextual cues to derive the requested act).

The request supportive moves are used to either mitigate the illocutionary force of a request. There are six of them: 1) preparator (preparing the recipient for the upcoming request by asking about the recipient's availability), 2) getting a precommitment (asking recipient for initial agreement to consider performing a request), 3) grounder (reasons, explanations, or justifications for the request) e, 4) disarmer (removing any potential objections the recipient might raise), 5) promise of reward (a reward due on fulfillment of request), 6) imposition minimizer (reducing the imposition of the request).

\section{Methodology}

\subsection{E-mail corpus}

In this study, a corpus of 90 authentic academic e-mails of request was analyzed. The emails were collected from a diverse group of participants $(n=12)$ in a graduate class at a university in the southeast of the U.S. The group consisted of eight native and four advanced non-native English speakers. Six of the participants were male, while the other six were female. They all held educational positions including teaching and advising in different academic contexts mainly at the university level. The age range of the group was 25-50. In order to build the corpus, each participant was asked to provide the last three e-mails of request that they sent and the last ten e-mails of request that they received at the beginning of the course term in Fall 2013. Participants were asked to specify information regarding nationality, age, occupation, the relationship between the sender and recipient, as well as additional contextual information relevant to the purpose of each e-mail message. The information about the relationship between the sender and recipient was used to determine the PD variable for each e-mail message. For data confidentiality purposes, all participants were asked to remove any identifying information ${ }^{2}$ pertaining to the senders and recipients of the e-mails, such as first and last names, institution names, e-mail addresses, date of the e-mail, etc. The e-mails of request in the corpus consisted of various types including requests for information, action, or clarification, asking for recommendation, appointment, and feedback.

\subsection{Data analysis}

\footnotetext{
${ }^{2}$ Participants were given specific instructions as to how they could blind the e-mails with examples. In the instructions participants were specifically asked not to share e-mail messages that contained sensitive or confidential information.
} 
All the e-mails in the corpus were initially coded based on the PD relationships elicited from the contextual information pertaining to social rank or occupation and closeness or distance between the senders and the recipients. In so doing, based on Scollon, Scollon, and Jones' (2012) categorization of face systems, three initial groups were formed: hierarchical, deference, and solidarity. The hierarchical group was further divided into two sub-groups based on the power status of the sender and the recipients of the e-mails. These were named hierarchical (sender $+\mathrm{P})$ and hierarchical (recipient $+\mathrm{P}$ ). The rationale behind this purposeful grouping is to see whether or not the social status or rank influences the request perspective, strategies, and supportive moves. Examples of social ranks or titles that were used to group the senders and recipients included university advisor, undergraduate student, graduate student, researcher, professor, colleagues at a university, and college administrator. The resultant face system groups included discourse contexts congruent with their respective face system. Table 1 shows examples of sender-recipient relationships for each face system group:

Table 1. The categorization of face systems by different e-mail sender and recipients

\begin{tabular}{|c|c|c|c|c|}
\hline & \multicolumn{4}{|c|}{ Face System } \\
\hline & $\begin{array}{l}\text { Hierarchical } \\
(\text { sender }+\mathrm{P})\end{array}$ & $\begin{array}{l}\text { Hierarchical } \\
(\text { recipient }+\mathrm{P})\end{array}$ & Deference & Solidarity \\
\hline Sender & $\begin{array}{l}40-50^{*}, \text { female, } \\
\text { American, } \\
\text { college } \\
\text { administrator }\end{array}$ & $\begin{array}{l}25-35, \text { male, } \\
\text { Italian, graduate } \\
\text { student, instructor }\end{array}$ & $\begin{array}{l}\text { 25-35, male, } \\
\text { American, } \\
\text { university advisor }\end{array}$ & $\begin{array}{l}\text { 25-30, female, } \\
\text { Chinese, graduate } \\
\text { student }\end{array}$ \\
\hline Recipient & $\begin{array}{l}\text { 45-50, female, } \\
\text { American, staff } \\
\text { assistant }\end{array}$ & $\begin{array}{l}\text { 40-50, female, } \\
\text { American, } \\
\text { university } \\
\text { professor }\end{array}$ & $\begin{array}{l}30-40, \text { female, } \\
\text { American, } \\
\text { university advisor }\end{array}$ & $\begin{array}{l}25-30, \text { male, } \\
\text { Turkish, graduate } \\
\text { student }\end{array}$ \\
\hline Relationship & $\begin{array}{l}\text { Sender is } \\
\text { recipient's } \\
\text { supervisor }\end{array}$ & $\begin{array}{l}\text { Recipient is the } \\
\text { instructor of the } \\
\text { course sender is } \\
\text { attending }\end{array}$ & $\begin{array}{l}\text { Sender and } \\
\text { recipient are } \\
\text { colleagues in } \\
\text { separate } \\
\text { departments }\end{array}$ & $\begin{array}{l}\text { Sender and } \\
\text { recipient are } \\
\text { students in the } \\
\text { same graduate } \\
\text { program }\end{array}$ \\
\hline
\end{tabular}

* Age range

After the PD relationships between the senders and recipients in all the e-mails were identified, request features such as head acts, perspectives, strategies, and mitigating supportive moves were coded for each e-mail based on the CCSARP coding manual (Blum-Kulka, House \& Kasper 1989; Blum-Kulka \& Olshtain 1984). The basic unit of analysis was the utterance or 
sequence of utterances in the emails that contained the speech act of request. The request sequence $^{3}$ consisted of the head act and adjunct(s) to the head act. The request perspective was determined by the use of pronouns in the head act. Second, the request strategy was identified based on the pragmalinguistic forms in the request head act. Finally, the request mitigating supportive moves were identified based on the information preceding or following the request head act.

\section{Results}

\subsection{Request perspectives}

Table 2 below shows the total number of occurrences and percentages of four request perspectives by each group. The analysis revealed that hearer dominance was the most frequent request perspective in the entire corpus $(39 \%)$ followed by speaker dominance $(37 \%)$. Hearer dominance was found to be the most frequent request perspective in the hierarchical (recipient+P) group, meaning that, due to the relative power difference, senders tend to explicitly refer to the recipient who has more power than the sender. On the contrary, hearer dominance was less common in the hierarchical (sender+P) group in which senders have more power than recipients. Therefore, it can be concluded that when email senders have more power than the recipients, they tend not to refer to recipients. Additionally, the deference face system also displayed hearer dominance more frequently than other request perspectives. This could be attributed to the fact that when senders and recipients have distant independence $(+D)$, senders usually explicitly refer to recipients. Below is an example for the use of hearer dominance:

(1) Hierarchical (recipient $+P$ )

$<$ Subject Line: refund $>$

Hello mam,

How are you? Still I haven't got any response or e-mail from finance office. Will you please get information for me that when can i get the refundable money ?Because, me and my friend rented a house here and we have to buy a lot of things and also i have to pay my tuition fees. It will be so kind if you talk to them. Thank you.

${ }^{3}$ Blum-Kulka \& Olshtain (1984) included address term(s) in the analysis of request sequence. However, they argued that the nucleus of the speech act (head act) is the part of the sequence that can independently realize the act of requesting regardless of the other elements. The present study focused on the realization of speech acts of request at the utterance level, therefore, the analysis exclusively focused on the head act and adjuncts to head act and address forms were not included in the analysis. 
your obedient student,

[first name and last name]

Table 2. Frequency of request perspectives in face systems

\begin{tabular}{cccccc}
\hline Request Perspective & $\begin{array}{c}\text { Hierarchical } \\
(\text { sender }+\mathrm{P}) \\
(\mathrm{n}=20)\end{array}$ & $\begin{array}{c}\text { Hierarchical } \\
(\text { recipient }+\mathrm{P}) \\
(\mathrm{n}=32)\end{array}$ & $\begin{array}{c}\text { Deference } \\
(\mathrm{n}=29)\end{array}$ & $\begin{array}{c}\text { Solidarity } \\
(\mathrm{n}=9)\end{array}$ & TOTAL=90 \\
\hline Hearer dominance & 4 & 14 & 12 & 5 & 35 \\
Speaker dominance & 7 & 14 & 9 & 3 & $39 \%$ \\
Speaker/hearer dominance & 1 & 0 & 3 & 0 & $37 \%$ \\
Impersonal & 8 & 4 & 5 & 1 & $4 \%$ \\
\end{tabular}

Following hearer dominance, speaker dominance was found to be the second most frequently used request perspective (37\%). Below is an example from the deference group:

(2) Deference

$<$ Subject Line: [program name] Program-VISIT TO CLASSES PLEASE READ>

Dear colleagues:

As it is customary, we ask for your permission to inform your classes about our [program name blocked] Study Abroad Program. We ask for 5 minutes of your class time. Prof. [first name last name] and I will be by either right at the start of class or 5 minutes before the end. We will begin our visits on Tuesday September 3rd. PLEASE LET US KNOW IF THIS IS OK.

Thank you!

Best,

[first name last name]

The distribution of speaker dominance differed among four face systems. The hierarchical (recipient+P) group had the highest use of this perspective, meaning that e-mail senders tend to refer to themselves explicitly when the recipients have a higher power status. 
Conversely, in e-mails where the senders had more power than the recipients, the use of speaker dominance as a request perspective was less frequent. The next face system group in which the use of speaker dominance was relatively high was the deference group. Similar to the frequency of hearer dominance in this group, when there is distant independence between the senders and recipients, senders may opt to explicitly refer to themselves in e-mail requests.

The speaker/hearer dominance was the least frequently used request perspective found only in $4 \%$ of the corpus. This perspective was found in only four emails, three of which were in the deference face systems group. Below is an example from the corpus:

(3) Deference

$<$ Subject Line: Meeting?

Dear [first name], $\cdots$

I was wondering if we could have a brief meeting to discuss my annual evaluation/performance at [workplace name] before it gets really hectic next week. I keep a record of all my professional evaluations, thus I would love to talk about my second and final year at [workplace name blocked] as an instructor like we did last year (I'd love to catch up with you if we can in the meantime?: $[\ldots]$

I look forward to hearing from you.

Best, [e-mail signature of the sender]

The impersonal perspective, which involves passivized constructions and avoidance of pronoun forms, was the third most frequently used request perspective by $20 \%$ in the corpus. This perspective was most commonly observed in the hierarchical (sender+P) face systems. In line with the rarity of the hearer and speaker dominance in this group, it seems that senders who have higher power status than recipients tend to adopt an impersonal perspective, which means that they avoid using pronouns and prefer passivized constructions in which there are no explicit pronouns. On the contrary, this perspective was less frequent in hierarchical (recipient $+\mathrm{P})$ and deference groups and almost non-existent in solidarity face systems. Thus, it could be posited that when the power distance gap between e-mail senders and recipients is smaller, the emails of request tend to show more personalized and active voices, whereas the perspective becomes 
more impersonal when there is a bigger power distance gap between the senders and recipients. Below is an example of showing the impersonal perspective:

(4) Hierarchical (recipient $+P$ )

$<$ Subject Line: Request to reinstate Student Organization - [organization name] $>$ Dear [first name],

I am writing this email because the student organization [organization name] was deactivated in May 2013. This organization was last led by first and lastname and the previous advisor for the organization, Dr. [last name], is still our current advisor. We still have a bank account and an advisor and we would like to get the organization going again for the Fall. We have a lot of new interested members, so how would it be possible to reactivate the organization and the bank account for this Fall semester?

Sincerely,

[first and last name]

Figure 1 displays the distribution of request perspectives across four face system groups.

Overall, it appears that hearer dominance is the most common request perspective in all four face system groups followed by speaker dominance and impersonal. As the findings of this study indicate, the request perspective in e-mail communication in academic settings is affected by the different PD relationships between the senders and recipients. For instance, speaker dominance in hierarchical systems indicates the principal performer in the speech act of request, suggesting that e-mail users with institutional power tend to emphasize individuality. On the other hand, in systems like solidarity and deference where discourse participants do not assume power differences prefer more hearer- or audience dominant perspectives in their requests. This finding lends support to Scollon et al.'s (2012) involvement politeness strategies (also known as solidarity politeness) in that hearer dominance as a request perspective demonstrates e-mail users desire to be connected to one another. Furthermore, it should be noted that in the hierarchical $($ recipient $+\mathrm{P})$ group, both hearer and speaker dominance was found to be equal. This could be attributed to the fact that e-mail senders who have relatively lower power status than the recipients tend to recognize the presence of the recipient in their request as well as their own. The presence of both hearer and speaker dominance in e-mails where the recipient is $+\mathrm{P}$ can be interpreted as an independence politeness strategy employed by senders with -P. For instance, in 
e-mail 1, the sender (-P) uses both speaker dominance with the personal pronoun 'I', as well as 'you' to indicate hearer dominance. Additionally, in the same e-mail, independence politeness strategies can be observed in the use of address forms (e.g. mam) as well as in sender's providing an option in the realization of the request (It will be so kind if you talk to them).

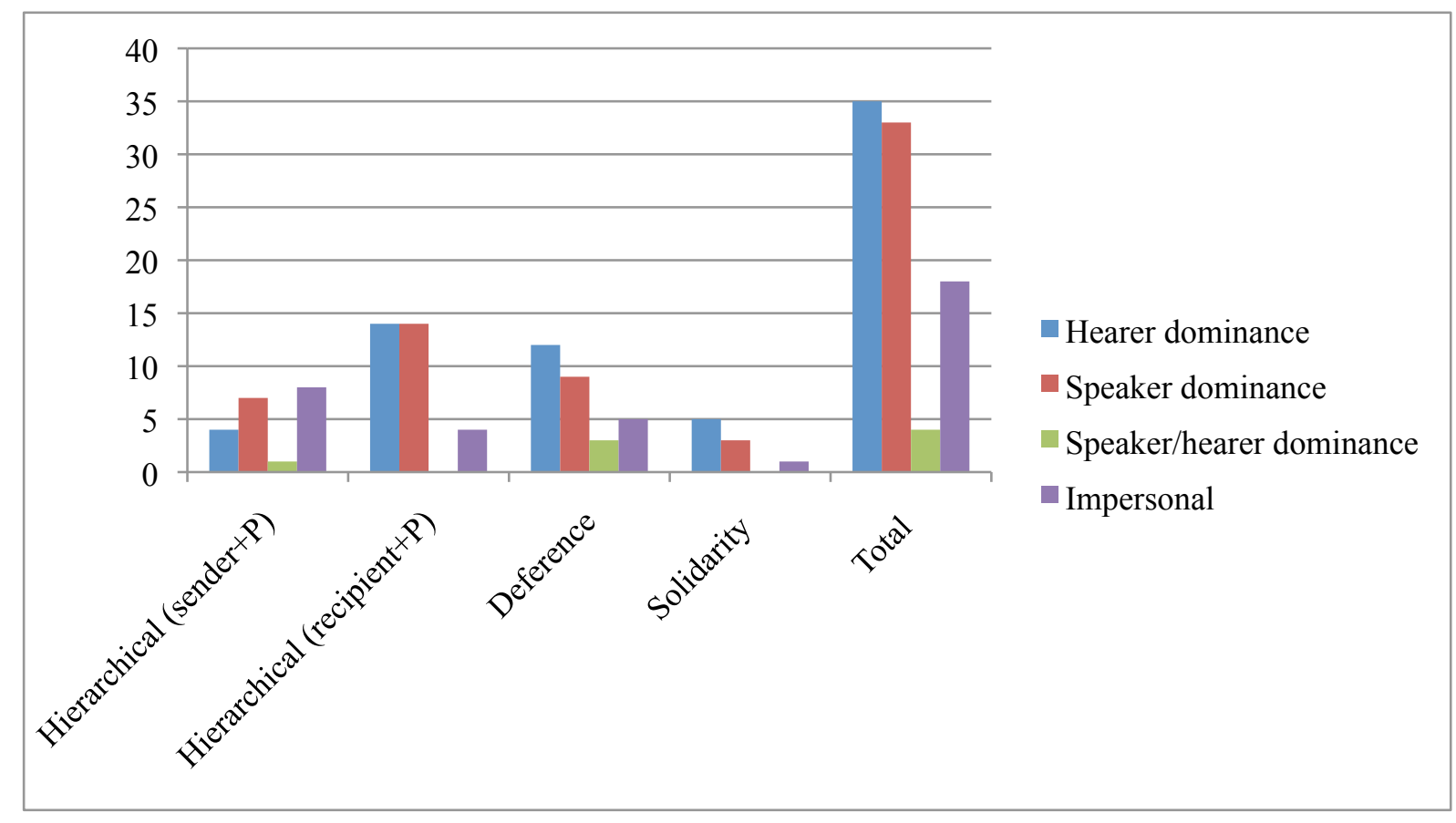

Figure 1. The distribution of the request perspectives in face systems

\subsection{Request Strategies}

Table 3 below summarizes the number of occurrences and percentages of the request strategies by group. The results indicate that the most frequent strategy is the preparatory by $49 \%$. The use of this strategy is the most common in the hierarchical (recipient $+\mathrm{P}$ ) group, followed by the deference group. The preparatory strategy is indicated by the reference to the condition for the plausibility and realization of the action being requested with the use of conditionals or modality forms. Therefore, it can be said that e-mail senders tend to use a variety of pragmalinguistic forms in order to minimize the directness of the request when the recipient has a higher power status. However, as indicated by the results in Table 3, the use of the preparatory strategy is the least frequent in the hierarchical (sender+P) group, indicating that email senders with higher power status do not exploit these particular pragmalinguistic forms as often in their requests when the recipients have lower power status. Following the hierarchical (recipient $+\mathrm{P}$ ) group, the deference face system uses the preparatory request strategy more frequently than the hierarchical (sender+P) and solidarity face systems, suggesting that lack of 
familiarity between the senders and recipients causes senders to conform to indirect request strategies. The following is an example of the use of the preparatory strategy:

(5) Hierarchical (recipient $+P$ )

$<$ Subject Line: Classroom Observation $>$

Hello

I am a student taking [course title] for the college of education and was wondering

if I could observe your class on 7/3 at 8:35am. Thank you for your consideration.

Table 3. Frequency of request strategies in face systems

\begin{tabular}{|c|c|c|c|c|c|}
\hline \multirow[b]{2}{*}{ Request strategy } & \multicolumn{5}{|c|}{ Face System } \\
\hline & $\begin{array}{c}\text { Hierarchical } \\
(\text { Sender }+\mathrm{P}) \\
(\mathrm{n}=20)\end{array}$ & $\begin{array}{c}\text { Hierarchical } \\
(\text { Recipient }+\mathrm{P}) \\
(\mathrm{n}=32)\end{array}$ & $\begin{array}{c}\text { Deference } \\
\quad(n=29)\end{array}$ & $\begin{array}{l}\text { Solidarity } \\
\qquad(\mathrm{n}=9)\end{array}$ & $\mathrm{TOTAL}=90$ \\
\hline Mood derivable & 8 & 3 & 5 & 0 & $\begin{array}{c}16 \\
17 \%\end{array}$ \\
\hline Explicit performative & 2 & 3 & 2 & 0 & $\begin{array}{c}7 \\
7 \%\end{array}$ \\
\hline Hedged performative & 2 & 5 & 2 & 0 & $\begin{array}{c}9 \\
10 \%\end{array}$ \\
\hline Locution derivable & 1 & 1 & 3 & 1 & $\begin{array}{c}6 \\
6 \%\end{array}$ \\
\hline Want statement & 2 & 1 & 1 & 0 & $\begin{array}{c}5 \\
5 \%\end{array}$ \\
\hline Suggestory formula & 0 & 0 & 0 & 1 & $\begin{array}{c}1 \\
1 \%\end{array}$ \\
\hline Preparatory & 5 & 18 & 14 & 7 & $\begin{array}{c}44 \\
49 \%\end{array}$ \\
\hline Strong hint & 0 & 0 & 0 & 0 & 0 \\
\hline Mild hint & 0 & 0 & 1 & 0 & $\begin{array}{c}1 \\
1 \%\end{array}$ \\
\hline
\end{tabular}

Following the preparatory is the mood derivable which occurred in the $17 \%$ of the corpus. The hierarchical (sender $+\mathrm{P}$ ) group as the one that displayed the highest percentage in the use of this strategy. The mood derivable indicates the level of directness in the request through imperative, elliptical, or infinite forms. Thus, this particular finding suggests that when the power status of an e-mail sender is higher than that of the recipient, the sender can exploit more direct forms in the request without having to soften the imposition of the request. Similarly, following th hierarchical (sender+P) group, the face system of deference exploits the mood derivable relatively more frequently than other face systems, which might result from the distant 
independence of the e-mail users or lack of familiarity with one another. The following e-mail is an example that illustrates the use of this request strategy:

(6) Hierarchical (sender $+\mathrm{P}$ )

$<$ Subject Line: Project for next week $>$

We need an inventory of who is using which office in building $\mathrm{H}$ and which

offices are empty. Please do a walk through, and make sure all "empty" offices are actually "empty."

Thanks,

[first name]

The third most commonly occurring request strategy was the hedged performative, comprising $10 \%$ of the corpus. This strategy was observed mainly in the hierarchical $($ recipient $+\mathrm{P})$ group and is usually denoted by modifications in the requestive intent by modal verbs or less direct forms. The fact that this strategy was more frequent in the hierarchical (recipient $+\mathrm{P}$ ) group could be due to the perceived higher power status of the recipient compared to the sender. The following is an example of the use of this strategy:

(7) Hierarchical (recipient $+\mathrm{P}$ )

Dear Dr. Firstname Lastname,

I am a student in the MA Linguistics program doing my observation internship. I am currently observing Firstname's Name of class class and I am going to need 5 hours from a different teacher. I wanted to ask you if I could observe your Name of class class on Thursday of this week at 2:00pm. If so, I need to know the room number. Thank you for your help.

Best,

Firstname

Among the rarely used strategies are the explicit performative by $7 \%$, the locution derivable by $6 \%$, the want statement by $5 \%$, the suggestory formula and the mild hint by $1 \%$ each in the corpus. Strong hint as a request strategy was not found in any of the face systems. Figure 2 below displays the distribution of the most commonly used request strategies across four face system groups: 


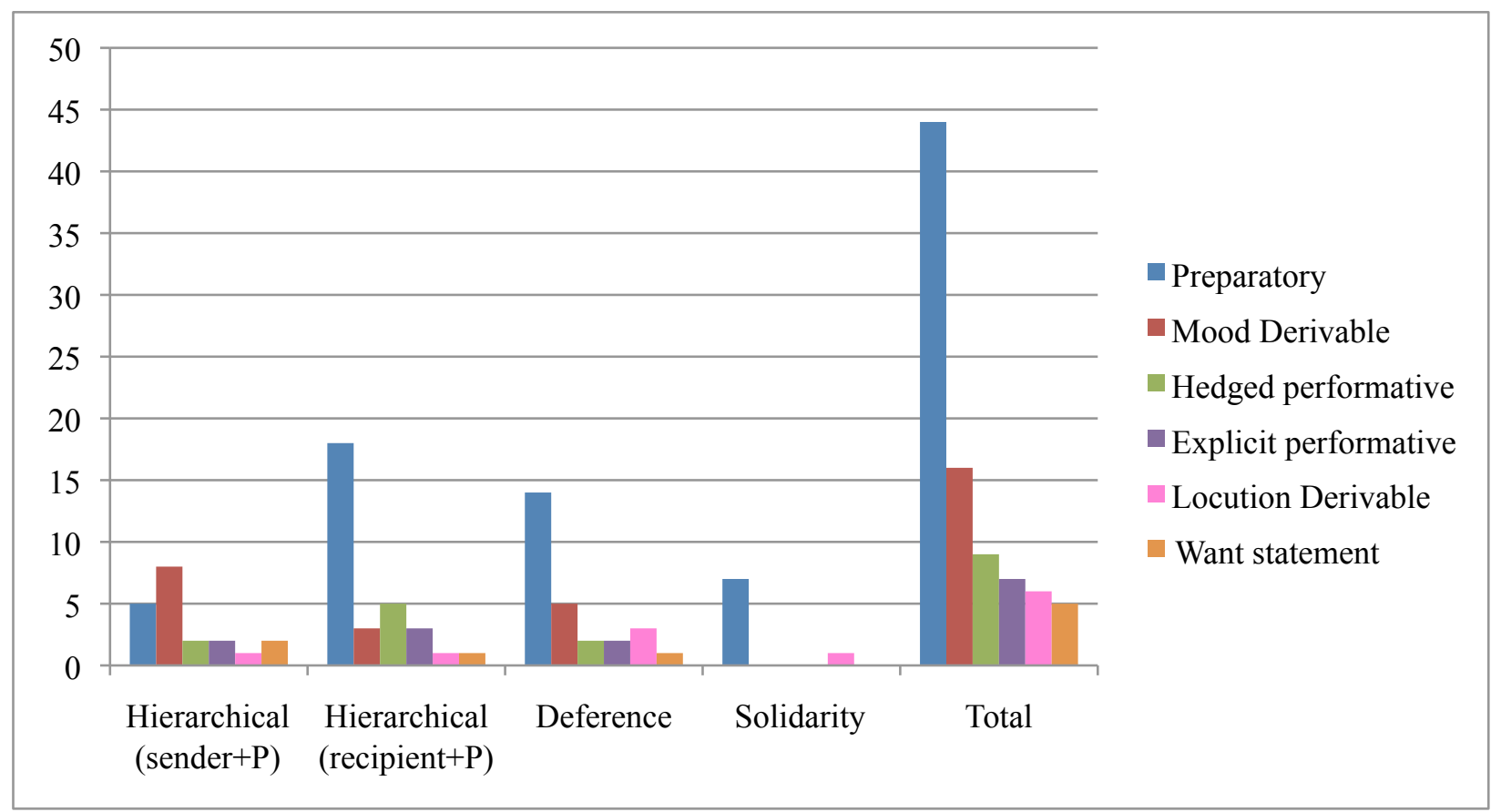

Figure 2. The distribution of request strategies across four face systems

In Table 4 below, the findings with respect to the request strategies have also been analyzed according to Blum Kulka et al.'s (1989) classification of (in)directness for request strategies. Direct strategies consisted of the mood and locution derivable, the explicit and hedged performatives, and the want statement, whereas conventionally indirect strategies included the preparatory and suggestory formula. The only nonconventional indirect strategy that was found in the corpus was the mild hint. As the results indicate, the hierarchical (sender $+\mathrm{P}$ ) was found to use direct strategies more frequently than other face systems ( $75 \%$ ) followed by deference $(45 \%)$ and hierarchical (recipient $+\mathrm{P})(41 \%)$, meaning that the wider the PD gap is between e-mail senders and recipients, the more direct the request strategies become. That said, the use of direct strategies was the least frequent in the solidarity group, which suggests that the lack of PD differentials leads senders and recipients to adopt more conventionally indirect strategies (78\%). By the same token, the use of conventionally indirect strategies was higher in the hierarchical (recipient $+\mathrm{P})(56 \%)$ and lower the hierarchical (sender+P) group (25\%). 
Table 4. Frequency of (in)directness of strategies in face systems

\begin{tabular}{lcccc}
\hline & \multicolumn{4}{c}{ Face System } \\
\hline \multirow{2}{*}{ Request strategy } & $\begin{array}{c}\text { Hierarchical } \\
(\text { Sender }+\mathrm{P})\end{array}$ & $\begin{array}{c}\text { Hierarchical } \\
(\text { Recipient }+\mathrm{P})\end{array}$ & Deference & Solidarity \\
\hline \multirow{2}{*}{ Direct } & 15 & 13 & 13 & 1 \\
& $75 \%$ & $41 \%$ & $45 \%$ & $11 \%$ \\
Conventionally indirect & 5 & 18 & 14 & 7 \\
Indirect & $25 \%$ & $56 \%$ & $48 \%$ & $78 \%$ \\
& 0 & 0 & 1 & 0
\end{tabular}

As the findings indicate, the PD differentials between e-mail senders and recipients influence the choice of request strategies. To illustrate, the use of the preparatory was significantly more frequent in the hierarchical (recipient $+\mathrm{P}$ ) than in the hierarchical (sender $+\mathrm{P})$, which suggests that individuals having lower social ranks than the recipients tend to minimize the directness or imposition of the requestive act by including an ability, feasibility, or willingness reference in their e-mails. Additionally, in accordance with Scollon et al.'s (2012) face systems theory, the use of the preparatory strategy by $(-\mathrm{P})$ participants when addressing $(+\mathrm{P})$ individuals can be attributed to independence politeness strategies to minimize threat or imposition. The hierarchical (sender $+\mathrm{P}$ ) group exhibited a higher percentage in the use of the mood derivable than other groups, indicating that the use of the imperative form in e-mails of request is more common in the hierarchical (sender $+\mathrm{P}$ ) since users with more power and authority tend to exploit more direct forms and do not need to mitigate the directness of their requestive acts. Similarly, the use of the explicit performative strategy was higher in the hierarchical (sender $+\mathrm{P}$ ) group than all the other groups, suggesting that power equates with more directness in academic e-mail requests. Finally, of all the four face systems, the solidarity group does not seem to use other request strategies as frequently as the preparatory. This could be attributed to the lack PD differentials as the members of this face system group are equal to one another with respect to power status and familiar with one another.

\subsection{Request mitigating supportive moves}

Table 5 below summarizes the number of occurrences and percentages of request mitigating supportive moves by group. Among all the mitigating supportive moves, the grounder was the most frequently used one (73\%). The frequency of the use of the grounder in all four face system groups was relatively similar. The deference group was found to have the highest 
percentage in the use of grounder, followed by the hierarchical (recipient $+\mathrm{P}$ ) and the hierarchical $($ sender $+\mathrm{P})$. Even though the grounder was the least frequent supportive move in the solidarity group compared to the other face system groups, it was the most frequently used supportive move in this group compared to other supportive moves. In fact, it should be noted that the solidarity group was the only face system group that did not use a variety of supportive moves. This could be related to (-P) and (-D) relationships between the e-mail senders and recipients. That is, when email senders and recipients know each other and they do not have power differences, they do not exploit supportive moves in their request emails as much as in other face systems. Conversely, in other face system groups such as hierarchical and deference, the use of the grounder is more frequent, indicating that $(+\mathrm{P})$ and $(+\mathrm{D})$ variables can account for the realization of requests in e-mails. Below is an example from the deference group of the use of grounder which provides the reason for the request:

(8) Deference

$<$ Subject Line: Email for your students $>$

Hola!

The following information and survey play a vital role in the development of language programs and cultural skills in our university, please open the link and answer the question.

[the link to the survey]

Gracias,

[first name last name]

Following the grounder was the imposition minimizer by $9 \%$, and this move was mainly used in the hierarchical (recipient $+\mathrm{P}$ ) group. This finding confirms that senders tend to minimize the imposition of their requests when the recipients have a higher status. The third most frequently used supportive move was the preparator by $7 \%$. Similarly, the findings indicate that the preparator is more frequently used in the hierarchical (recipient $+\mathrm{P})$. The preparator is indicated by a statement that precedes the request and alerts the interlocutor that a request is about to be made or by a question that asks about the availability of the interlocutor or asks for his/her permission to make the request. Below is an example:

(9) Hierarchical (recipient $+\mathrm{P}$ ) 
$<$ Subject Line: Printing Request on Department Letterhead $>$

Hello [first name],

I have a favor to ask of you. I need a request for a desk copy of a textbook printed

on a department letterhead, and I was told you're the one who can help me with

that. If so, could you please print the attached information for me with an official

letterhead? And could you please make sure I have the address right? Thank you

so much for your help.

[first name]

Table 5. Frequency of request mitigating supportive moves in face systems

\begin{tabular}{|c|c|c|c|c|c|}
\hline \multirow[b]{2}{*}{$\begin{array}{c}\text { Mitigating supportive } \\
\text { moves }\end{array}$} & \multicolumn{5}{|c|}{ Face System } \\
\hline & $\begin{array}{l}\text { Hierarchical } \\
(\text { sender }+\mathrm{P}) \\
(\mathrm{n}=20)\end{array}$ & $\begin{array}{c}\text { Hierarchical } \\
\text { (recipient }+\mathrm{P}) \\
(\mathrm{n}=32)\end{array}$ & $\begin{array}{l}\text { Deference } \\
(\mathrm{n}=29)\end{array}$ & $\begin{array}{l}\text { Solidarity } \\
\qquad(\mathrm{n}=9)\end{array}$ & TOTAL $=90$ \\
\hline Preparator & 1 & 4 & 1 & 1 & $\begin{array}{c}7 \\
7 \%\end{array}$ \\
\hline $\begin{array}{c}\text { Getting a } \\
\text { precommitment }\end{array}$ & 1 & 1 & 0 & 0 & $\begin{array}{c}2 \\
2 \%\end{array}$ \\
\hline Grounder & 14 & 20 & 25 & 7 & $\begin{array}{c}66 \\
73 \%\end{array}$ \\
\hline Disarmer & 0 & 0 & 3 & 0 & $\begin{array}{c}3 \\
3 \%\end{array}$ \\
\hline Promise of a reward & 1 & 5 & 1 & 0 & $\begin{array}{c}2 \\
2 \%\end{array}$ \\
\hline Imposition minimizer & 2 & 4 & 2 & 0 & $\begin{array}{c}8 \\
9 \%\end{array}$ \\
\hline
\end{tabular}

The other supportive moves such as getting a precommitment (2\%), disarmer (3\%), and promise of a reward (2\%) were not frequently observed in the corpus across different face systems. One important finding regarding these supportive moves is that all face groups exhibited minimal use of the promise of a reward, but the hierarchical (recipient $+\mathrm{P})$. It might be posited that the promise of a reward is congruent with high social status or power, thus, is exploited by users when communicating with others possessing power.

Figure 3 displays the distribution of the three most frequently used mitigating supportive moves in e-mails of request. Overall, in all four groups the grounder was the most frequently used mitigating supportive move. This finding confirms that e-mails, as a mode of asynchronous communication, provide ample time and space for users to state reasons for the requests being 
made. Therefore, regardless of the face system, users tend to give reasons or justifications for their requests. As can be seen from the figure below, the use of the grounder is relatively higher in the deference group and lower in the solidarity group, which suggests that the tendency to provide reasons or explanations for requests in academic e-mails is determined by the particular PD variables between the sender and recipients.

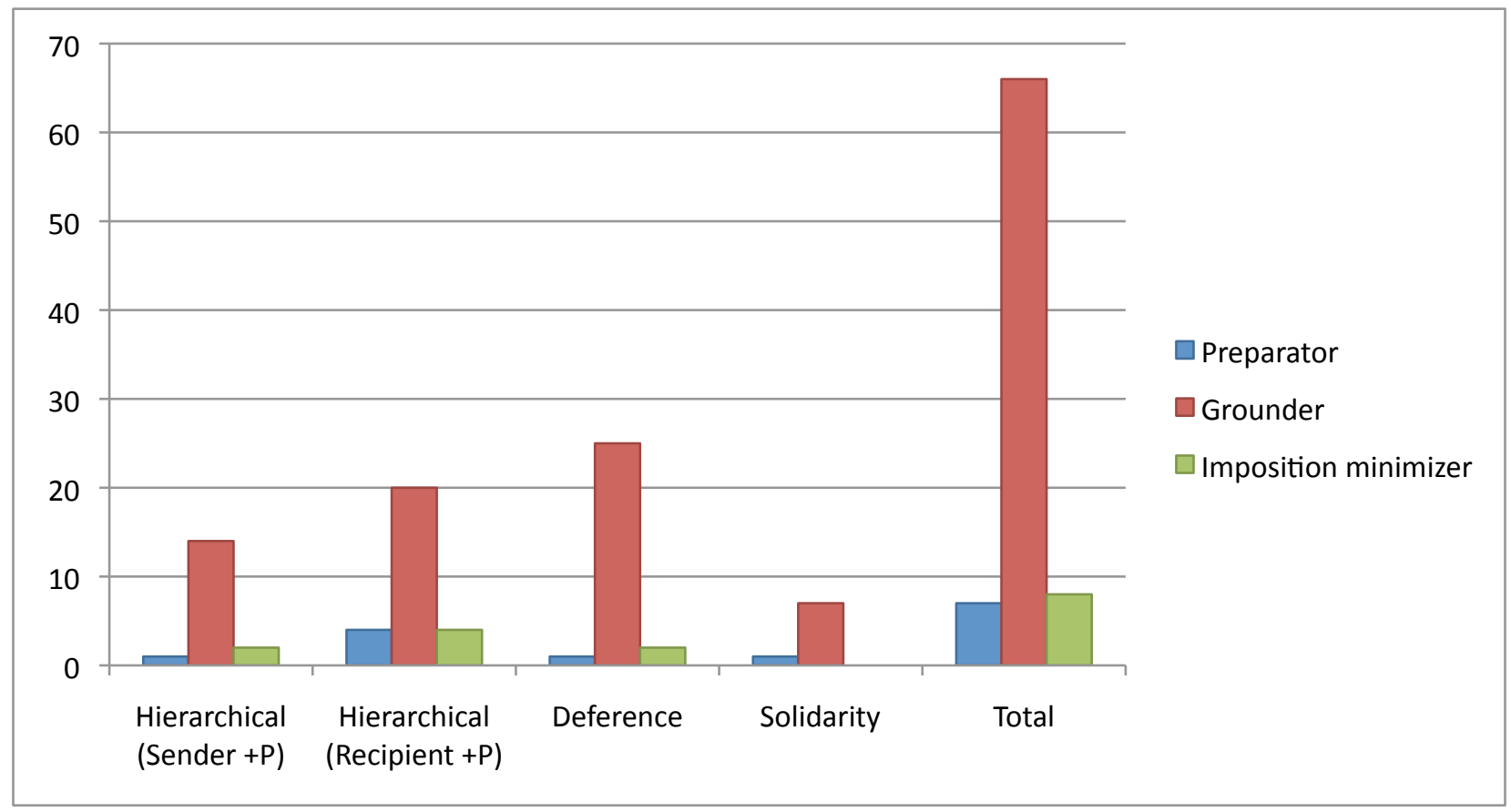

Figure 3. The distribution of mitigating supportive moves across four face systems

\section{Discussion}

The present study offers an original analysis of the pragmalinguistic features of academic emails informed by two interrelated frameworks namely the Blum-Kulka et al.'s (1989) CCSARP project and Scollon et al.'s (2012) face systems approach. As described previously, most previous research on the impact of hierarchical differences between e-mail users on e-mail style and conventions focused on openings/greetings/closings (Bjørge 2007; Bou-Franch 2011), forms of address (Economidou-Kogetsidis 2011), textual identities and writing styles (Liu 2011; Panteli 2002), and syntactic and lexical politeness (Biesenbach-Lucas 2007; Soler 2013). The present study enhances our understanding of the interface between the speech act of request and PD differentials operationalized as face systems (Scollon, Scollon, \& Jones 2012) between senders and recipients in academic settings with respect to request perspectives, strategies and supportive moves. Additionally, unlike most previous research that mainly focused on the effects of PD variables on e-mails of request within strictly sender-focused non-native English speaking 
populations, specifically student-faculty interactions with an interlanguage and cross-cultural pragmatics focus (Biesenbach-Lucas 2007; Bjørge 2007; Bloch 2002; Economidou-Kogetsidis 2011), the present study incorporates a variety of relationships between e-mail senders and recipients, thereby filling in a research gap which was called for in Lorenzo-Dus and Bou-Franch (2013).

The findings of this study also contribute to the theoretical framework of the CCSARP project (Blum-Kulka, House \& Kasper 1989; Blum-Kulka \& Olshtain 1984) with regard to both situational and individual variation. The PD variables conceptualized within the face systems approach (Scollon, Scollon \& Jones 2012) were found to lead to variation in the use of request perspectives in e-mail communication. In each face system group, regardless of individual variation in terms of social status or occupation, e-mail users' perspective in their requests was predominantly hearer- and speaker-oriented. The use of the impersonal request perspective mainly in the hierarchical (sender $+\mathrm{P}$ ) also indicates that as the relative gap in power or rank between e-mail sender and recipient increases, the request perspective changes direction and moves towards a more formal and impersonal perspective. As Blum-Kulka, House, and Kasper (1989) suggests, the choice of request perspective determines the social meaning being conveyed, and the use or avoidance of e-mail sender or recipient references can influence the level of coerciveness of the request.

The discussion is now directed to the use of request strategies in the e-mail corpus. The findings indicated a dominant use of two major request strategies, namely the preparatory and the mood derivable. Based on the CCSARP coding manual (Blum-Kulka, House \& Kasper 1989), each strategy demonstrates a different level of directness, the former being a conventionally indirect and the latter a direct strategy. As Biesenbach-Lucas (2006) emphasized, the choice of direct or indirect request strategies may be influenced by factors other than the native or non-native speaker status of the users, addressee, level of imposition, or medium. Analyzing authentic e-mail data, the present study demonstrates that e-mail users in academic settings employ conventionally indirect request strategies more frequently than direct strategies. This finding is in line with Chen (2001) who also found that American and Taiwanese graduate students preferred the query preparatory strategy in their e-mails of requests. In addition, regardless of the native or non-native status, the query preparatory was one of the most frequently used strategies among Peninsular Spanish and British English speakers in Lorenzo- 
Dus and Bou-Franch (2013). The finding that the hierarchical (sender+P) group used the mood derivable as a direct request strategy relatively more frequently than other request strategies suggests that the power variable is congruent with directness. In addition, the use of direct strategies by e-mail senders who are hierarchically ranked higher than the recipients supports Panteli's (2002) finding that e-mail communication provides flexibility in terms of the norms of interactions in a given context.

With regard to the use of request supportive moves, the present study has findings similar to previous research. As shown in numerous studies of the speech act of requests (Blum-Kulka $\&$ Olshtain 1984; Bou-Franch 2006; Economidou-Kogetsidis 2011; Hassall 2001; Lorenzo-Dus \& Bou-Franch 2013), the grounder was also found to be the most frequently used supportive move in the present study. As Hassall (2001) suggests, the use of grounder as a source of reasons and explanations can stimulate hearer's cooperation with the request being made. In conjunction with the hearer-dominance, the hearer-oriented nature of the grounder as a request supportive move strengthens the argument that e-mail users prefer to indicate the presence of the audience in their e-mails of request, thereby increasing the degree of positive politeness (Brown \& Levinson 1978) and decreasing the face-threatening conditions of the requestive acts. In that respect, it may be posited that regardless of the hierarchical differences between the senders and recipients, the choice of voice in e-mail communication tends to be predominantly agent-oriented. Therefore, the present study lends support for the involvement component of the face systems framework of Scollon, Scollon, and Jones (2012) in that agent-orientedness in e-mail communication linguistically manifests itself to indicate group-membership in CMC discourse communities.

The present study has a number of limitations that need to be noted. Firstly, the corpus analyzed in this study is relatively small. A larger corpus that involves a broader array of occupations or social ranks might lead to differences in the distribution of the perspectives, strategies, and supportive moves. Second, variables such as gender, native or non-native English user status, nationality, and culture were outside the scope of this study. Additionally, the corpus was created based on the selections of the participants, which may have limited the variety of relationships included in the corpus and the particular interactional styles exploited by e-mail users in their request patterns. Finally, the perceptions of e-mail users about the use of request patterns as determined by the power differentials as categorized in the present study may be 
investigated through qualitative methods of inquiry, such as interviews or surveys, to better account for the effect of PD variables on observed linguistic choices in e-mail communication.

\section{Conclusion}

The present study has a number of implications for future CMC research in terms of the technological, social, and pragmatic aspects of online communication. The present study is an example of the shift from medium-related to user-related patterns of language use emphasizing the interface between online practices of individuals and the relational and social aspects of language (Androutsopoulos 2006). More precisely, a user-centered approach to computermediated discourse seeks out to describe the pragmatic and social functions of discourse based on relational, personal or group dynamics (Androutsopoulos 2013).

Along with the increasing level of multimodality in digital environments, the study of PD differentials in online platforms where different modes of communication such as text, video, and voice on users' linguistic choices to perform different speech acts emerges as an important area of investigation. The impact of the affordances of different synchronous and asynchronous modes of CMC (e.g. text messaging, instant messaging, etc.) on the linguistic choices of users with regard to making requests could be investigated. Furthermore, as Androutsopoulos (2013) suggests, "the interpretation of linguistic findings can benefit from some awareness of the social and situational contexts of the data" (p. 240). Therefore, investigating the impacts of sociodemographic variables is important and crucial in CMC research.

\section{References}

Androutsopoulos, Jannis. 2006. Introduction: sociolinguistics and computer-mediated communication. Journal of Sociolinguistics 10, 4: 419-438.

Androutsopoulos, Jannis. 2013. Online Data Collection. In: Data Collection in Sociolinguistics: Methods and Applications. Christine Mallinson, Becky Childs, and Gerard van Herk (eds.) 237-249. London: Continuum.

Baron, Naomi S. 1998. Letters by phone or speech by other means: the linguistics of email. Language and Communication 18: 133-170. 
Biesenbach-Lucas, Sigrun. 2007. Students writing e-mails to faculty: an examination of epoliteness among native and non-native speakers of English. Language Learning and Technology 11, 2: 59-81.

Bjørge, Anne. K. 2007. Power distance in English lingua franca email communication. International Journal of Applied Linguistics 17, 1: 60-80.

Bloch, Joel. (2002). Student/teacher interaction via email: the social context of Internet discourse. Journal of Second Language Writing 11: 117-134.

Blum-Kulka, Shoshana \& Elite Olshtain. 1984. Requests and apologies: a cross cultural study of speech act realization patterns. Applied Linguistics 5: 196-213.

Blum-Kulka, Shoshana, Juliane House, and Gabriele Kasper (eds.) 1989. Cross-Cultural Pragmatics: Requests and Apologies. Norwood, N.J.: Ablex.

Bou-Franch, Patricia. 2006. Solidarity and deference in Spanish Computer-Mediated Communication: A Discourse-Pragmatic Analysis of Students' Emails to Lecturers. In: Ways into discourse, Patricia Bou-Franch (ed.), 61-79. Granada: Comares.

Bou-Franch, Patricia. 2011. Openings and closings in Spanish email conversations. Journal of Pragmatics, 43: 1772-1785.

Brown, Penelope \& Stephen C. Levinson. 1978. Universals of Language Use: Politeness Phenomena. In Questions and Politeness, Esther N. Goody (ed.), 56-324. Cambridge: Cambridge University Press.

Brown, Penelope \& Stephen C. Levinson. 1987. Politeness: Some Universals in Language Use. Cambridge: Cambridge University Press.

Chen, Chi-Fen E. 2001. "Making e-mail requests to professors: Taiwanese vs. American students". Paper presented at the American Association of Applied Linguistics Conference, St. Louis, Mo.

Crystal, David. 2001. Language and the Internet. Cambridge: Cambridge University Press. Economidou-Kogetsidis, Maria. 2011. "Please answer me as soon as possible": Pragmatic failure in non-native speakers' email requests to faculty. Journal of Pragmatics 43: 3193-3215. French, John R.P., and Bertram Raven. 1959. The Bases of Social Power. In Studies in Social Power, Dorwin Cartwright (ed). 150-167. Ann Arbor: University of Michigan Press. Hassall, Tim. 2001. Modifying requests in a second language. International Review of Applied Linguistics (IRAL) 39: 259-283. 
Herring, Susan. C. 2003. Computer-mediated Discourse. In: The Handbook of Discourse Analysis, Deborah Schiffrin, Deborah Tannen \& Heidi E. Hamilton (eds), 612-634. Malden, Mass.: Blackwell Publishing.

Herring, Susan C. 2007. A faceted classification scheme for computer-mediated discourse. Language@internet 4, 1: 1-37.

Hofstede, Geert. 2001. Culture's Consequences (2nd ed.). Thousand Oaks, Calif.: Sage. Kristiansen, Gitte \& Dirk Geeraerts. 2013. Introduction: contexts and usage in cognitive sociolinguistics. Journal of Pragmatics 52: 1-4.

Liu, Yichun. 2011. Power perceptions and negotiations in a cross-national email writing activity. Journal of Second Language Writing 20: 257-270.

Locher, Miriam. A. 2010. Introduction: Politeness and impoliteness in computer-mediated communication. Journal of Politeness Research 6: 1-5.

Lorenzo-Dus, Nuria \& Patricia Bou-Franch. 2013. A cross-cultural investigation of email communication in Peninsular Spanish and British English: the role of (in) formality and (in) directness. Pragmatics and Society 4, 1: 1-25.

Paltridge, Brian. 2012. Discourse Analysis ( $2^{\text {nd }}$ ed.). London: Bloomsbury.

Panteli, Niki. 2002. Richness, power cues and email text. Information \& Management 40, 2: 75 86.

Scollon, Ron, Suzanne W. Scollon and Rodney H. Jones. 2012. Intercultural Communication: A Discourse Approach (3rd ed.). Malden, Mass.: Blackwell Publishing.

Selvi, Ali F. \& Bedrettin Yazan. 2013. Teaching English as an international language. Alexandria, Va.: TESOL Press.

Soler, Eva. A. 2013. Pragmatic variation in British and international English language users' email communication: a focus on requests. Revista española de lingüistica aplicada, 26: $25-44$.

Varner, Iris and Linda Beamer. 2005. Intercultural Communication in the Global Workplace $\left(3^{\text {rd }}\right.$ ed.). Boston, Mass.: McGraw Hill.

\section{About the author}

Erhan Aslan is a doctoral candidate in the Second Language Acquisition and Instructional Technology program at the University of South Florida. He also works an instructor of academic 
English in the English Language Program at the same institution. His research interests include interlanguage pragmatics in adult second language users, individual differences in language learning, foreign language teacher education, and computer-mediated communication. He has published in international journals such as Canadian Modern Language Review, International Journal of Multilingualism, and Language Learning Journal.

\section{Address for correspondence}

University of South Florida

4202 E Fowler Ave FAO 100

Tampa, FL 33620

Email: easlan@usf.edu

Word Count 8,765 